\title{
Male cytogenetic evaluation prior to assisted reproduction proce- dures performed in Mar del Plata, Argentina
}

\author{
María N. Polii ${ }^{1,2,3}$, Lucía A. López Miranda3 ${ }^{3}$ Eduardo Daniel Gil3 ${ }^{3}$, Germán Justo Zanier ${ }^{3}$, Pedro Fernández Iriarte ${ }^{1,2}$, \\ Justo H. Mario Zanier ${ }^{3}$, Roberto $\mathrm{Coco}^{4}$ \\ ${ }^{1}$ Genetics Laboratory, Biology Department FCEyN, National University of Mar del Plata, Argentina \\ ${ }^{2}$ CONICET - The National Scientific and Technical Research Council, Argentina \\ ${ }^{3}$ Association of Human Genetics (AGHU) of Mar del Plata, Argentina \\ ${ }^{4}$ FECUNDITAS - Reproductive Medicine associated to Buenos Aires University, Argentina
}

\begin{abstract}
Objective: This paper aimed to estimate the frequency of occurrence and the types of chromosomal abnormalities found in 141 infertile men with abnormal semen parameters.

Methods: the frequency and type of chromosomal abnormalities were determined with male mitotic karyotype analysis from peripheral blood through chromosome banding techniques before assisted reproduction procedures. Results: In this series of 141 infertile men, 19 (13\%) had chromosomal anomalies and $35(25 \%)$ had polymorphic variants. The main chromosome abnormalities were reciprocal translocations and marker chromosomes in mosaic. Conclusions: These results stress the relevance of cytogenetic studies for infertile males as a diagnostic tool and a valuable input in genetic counseling.
\end{abstract}

Keywords: male infertility, assisted reproduction technology, chromosomal anomalies

\section{INTRODUCTION}

An estimated $15 \%$ of the cases of male infertility are caused by gene and chromosome anomalies. One in every 1,000 male newborns has abnormalities in their sex chromosomes leading to sterility in adult life. Furthermore, one in 500 newborns of the general population has a balanced chromosomal rearrangement contributing to infertility (Coco, 2013; Coco, 2015). In populations of infertile males, the frequencies of these defects are significantly higher and correlated with the severity of semen anomalies. Numerical sexual chromosome abnormalities like 47, $X X Y$ generally lead to infertility in adulthood, while balanced chromosome rearrangements determine infertility and possibly birth malformations, mainly partial monosomies or trisomies of the chromosomes involved, due to an abnormal segregation of the meiotic balanced rearrangement.

This paper aimed to establish the incidence of chromosomal abnormalities in a series of males with abnormal semen findings seen for infertility at different reproductive medicine centers in Mar del Plata before they were offered assisted reproduction technologies.

\section{MATERIALS AND METHODS}

Patients and methods

Between December of 2009 and May of 2013, 141 patients seen for infertility at several assisted reproduction centers were referred to the Association of Human Genetics to join a cytogenetic study. The patients were informed of the study's scope and were asked to give written consent before joining the study.

Conventional cytogenetic analysis in peripheral blood was performed along with the $\mathrm{G}$ banding technique with $\mathrm{a}$ resolution between 450 and 550 bands (Moorhead et al., 1960; Seabright, 1972). The high-resolution technique was performed using 5-bromodeoxyuridine (BUdR), 5-fluorodeoxyuridine (FUdR), and 3\% Giemsa staining (Dutrillaux, 1975).

\section{RESULTS}

Nineteen of the 141 mitotic karyotypes analyzed had chromosomal abnormalities, and 35 had polymorphic variants. The abnormalities found were reciprocal translocations, between autosomal chromosomes and/or between sex-autosomal chromosomes, Robertsonian translocation, pericentric inversion, an additional chromosomal segment, numerical sex chromosomes, autosome chromosomal mosaicisms, and supernumerary marker chromosomes. The cytogenetic findings are described in Table 1.

\section{DISCUSSION}

Nineteen patients had chromosomal abnormalities $(13 \%)$ and 35 had chromosomal variants $(25 \%)$. The percentage of chromosomal abnormalities found in infertile patients was consistent with previously published evidence (Coco et al., 2005). However, lower percentages of sex chromosome abnormalities were observed in patients with azoospermia when compared to previously published studies. In patients with homogeneous karyotype $47, \mathrm{XXY}$ or in cases of mosaicism with a normal cell line, one could attempt to retrieve intratesticular sperm and perform ICSI with or without analyzing the embryonic karyotype, as these patients are not at increased risk of having sperm aneuploidy when compared to patients with azoospermia and normal karyotypes, once only normal preleptotene spermatocytes can undergo meiosis (Sciurano et al., 2012).

Surprisingly, three patients presented with autosomal chromosome mosaicism. Two had trisomy 21 and one had trisomy 10 . The three patients with oligozoospermia were not at increased risk of sperm aneuploidy, once spermatocytes with an extra univalent cannot complete meiosis. However, when the mosaic is produced by a genic chromosomal instability, the predisposition to have children with the same or another mosaicism may be transmitted.

Five patients had exceedingly small mosaic markers, but the origin of the markers could not be identified. The frequency of occurrence of chromosome markers agrees with data reported previously. Unlike female carriers who are fertile and can transmit the marker, most males are infertile due to azoospermia or severe oligozoospermia. These patients can now benefit from ICSI. In such case, they should be offered embryonic karyotyping, once a type of trivalent could form in meiosis with the risk of abnormal segregation.

Five patients had reciprocal translocations, three of 
Table 1. Cytogenetic test results from 141 infertile men with abnormal spermograms

\begin{tabular}{|c|c|c|c|}
\hline $\begin{array}{c}\text { Chromosomal } \\
\text { alterations }\end{array}$ & $\begin{array}{c}\text { Number of } \\
\text { patients }\end{array}$ & Karyotype & $\begin{array}{l}\text { Spermatic } \\
\text { alteration }\end{array}$ \\
\hline $\begin{array}{l}\text { a) numerical sex } \\
\text { chromosome } \\
\text { numerical } \\
\text { abnormalities }\end{array}$ & $\begin{array}{l}1 \\
1 \\
1\end{array}$ & $\begin{array}{c}47, X X Y[20] \\
47, X X Y,[48] / 46, X Y[2] \\
46, X X[50]\end{array}$ & $\begin{array}{l}\text { Azoospermia } \\
\text { Azoospermia } \\
\text { Azoospermia }\end{array}$ \\
\hline $\begin{array}{l}\text { b) numerical } \\
\text { autosome } \\
\text { chromosome } \\
\text { alterations }\end{array}$ & $\begin{array}{l}1 \\
1 \\
1\end{array}$ & $\begin{array}{l}47, X Y,+10[3] / 46, X Y[97] \\
47, X Y,+21[3] / 46, X Y[97] \\
47, X Y,+21[2] / 46, X Y[98]\end{array}$ & $\begin{array}{l}\text { Oligozoospermia } \\
\text { Oligozoospermia } \\
\text { Oligozoospermia }\end{array}$ \\
\hline $\begin{array}{l}\text { c) mosaicism } \\
\text { markers }\end{array}$ & $\begin{array}{l}1 \\
1 \\
1 \\
1 \\
1\end{array}$ & $\begin{array}{c}47, \mathrm{XY}, 21 \mathrm{ps}+,+\operatorname{marc}[3] / 46, \mathrm{XY}, 21 \mathrm{ps}+[97] \\
47, \mathrm{XY},+\operatorname{marc}[3] / 46, \mathrm{XY}[47] \\
47, \mathrm{XY},+\operatorname{marc}[7] / 46, \mathrm{XY}[28] \\
47, \mathrm{XY}, 15 \mathrm{ps}+,+\operatorname{marc}[3] / 46, \mathrm{XY}, 15 \mathrm{ps}+[47] \\
47, \mathrm{XY},+\operatorname{mar}[6] / 46, \mathrm{XY}[44]\end{array}$ & $\begin{array}{l}\text { Oligozoospermia } \\
\text { Oligozoospermia } \\
\text { Azoospermia } \\
\text { Oligozoospermia } \\
\text { Oligozoospermia }\end{array}$ \\
\hline $\begin{array}{l}\text { d) reciprocal } \\
\text { translocations }\end{array}$ & $\begin{array}{l}1 \\
1 \\
1 \\
1 \\
1 \\
1\end{array}$ & $\begin{array}{c}46, \mathrm{XY}, \mathrm{t}(7 ; 10)(\mathrm{q} 22 ; \mathrm{q} 24.1)[20] \\
46, \mathrm{XY}, \mathrm{t}(13 ; 14)(\mathrm{q} 10 ; \mathrm{q} 10)[20] \\
46, \mathrm{XY}, \mathrm{t}(5 ; 20)(\mathrm{q} 31 ; \mathrm{p} 13)[30] \\
46, \mathrm{XY}, \mathrm{t}(7 ; 13)(\mathrm{q} 22 ; \mathrm{q} 34)[20] \\
46, \mathrm{X}, \mathrm{t}(\mathrm{Y} ; 11)(\mathrm{p} 11.3 ; \mathrm{p} 14)[20] \\
46, \mathrm{Y}, \mathrm{t}(\mathrm{X} ; 1)(\mathrm{q} 22.1 ; \mathrm{p} 22.1)[20]\end{array}$ & $\begin{array}{l}\text { Azoospermia } \\
\text { Azoospermia } \\
\text { Azoospermia } \\
\text { Azoospermia } \\
\text { Azoospermia } \\
\text { Azoospermia }\end{array}$ \\
\hline e) investments & 1 & $46, X Y, \operatorname{inv}(18)(p 11.1 q 23)[30]$ & Oligozoospermia \\
\hline $\begin{array}{l}\text { f) additional } \\
\text { segment }\end{array}$ & 1 & $46, X Y, \operatorname{add}(22)(p 12)[50]$ & Oligozoospermia \\
\hline $\begin{array}{c}\text { Polymorphic } \\
\text { variants }\end{array}$ & $\begin{array}{c}\text { Number of } \\
\text { patients }\end{array}$ & Karyotype & $\begin{array}{l}\text { Spermatic } \\
\text { alteration }\end{array}$ \\
\hline $1 \mathrm{qh}+$ & 1 & $46, X Y, 1 q h+$ & Azoospermia \\
\hline $9 \mathrm{ph}, 9 \mathrm{qh}+$ & 1 & $46, \mathrm{XY}, 9 \mathrm{ph}, 9 \mathrm{qh}+$ & Azoospermia \\
\hline $13 p s+$ & 2 & $46, X Y, 13 p s+$ & Oligozoospermia \\
\hline $14 \mathrm{ps}+$ & 4 & $46, X Y, 14 p s+$ & \\
\hline $13 p s+, 14 p s+$ & 1 & $46, \mathrm{XY}, 13 \mathrm{ps}+, 14 \mathrm{ps}+$ & Azoospermia \\
\hline $15 p s+$ & $\begin{array}{l}3 \\
1\end{array}$ & $\begin{array}{c}46, X Y, 15 p s+ \\
47, X Y, 15 p s+,+\operatorname{marc}[3] / 46, X Y, 15 p s+[47]\end{array}$ & $\begin{array}{l}\text { Oligozoospermia } \\
\text { Oligozoospermia }\end{array}$ \\
\hline $15 p s+, 21 p s+, 22 p s+$ & 1 & $46, \mathrm{XY}, 15 \mathrm{ps}+, 21 \mathrm{ps}+, 22 \mathrm{ps}+$ & Azoospermia \\
\hline $16 \mathrm{qh}+$ & 1 & $46, \mathrm{XY}, 16 \mathrm{qh}+$ & Azoospermia \\
\hline $21 \mathrm{ps}+$ & $\begin{array}{l}5 \\
1\end{array}$ & $\begin{array}{c}46, \mathrm{XY}, 21 \mathrm{ps}+ \\
47, \mathrm{XY}, 21 \mathrm{ps}+,+\operatorname{marc}[3] / 46, \mathrm{XY}, 21 \mathrm{ps}+[97]\end{array}$ & $\begin{array}{l}\text { Azoospermia/ } \\
\text { Oligozoospermia } \\
\text { Oligozoospermia }\end{array}$ \\
\hline $22 \mathrm{ps}+$ & 7 & $46, X Y, 22 p s+$ & $\begin{array}{l}\text { Azoospermia/ } \\
\text { Oligozoospermia }\end{array}$ \\
\hline 22 pstk+ & 1 & $46, X Y, 22 p s t k+$ & Oligozoospermia \\
\hline Yqh+ & 6 & $46, \mathrm{XYqh}+$ & $\begin{array}{l}\text { Azoospermia/ } \\
\text { Oligozoospermia }\end{array}$ \\
\hline
\end{tabular}

which autosome-autosome, one $\mathrm{Y}$-autosome translocation, and one $\mathrm{X}$-autosome translocation. All five patients had azoospermia. The frequency of occurrence of this finding was surprisingly higher when compared to previous reports. These translocations may interfere with the pairing of the involved chromosomes and arrest the meiotic division in the prophase stage (Sciurano et al., 2012). The patients were informed of the need to undergo testicular biopsies to retrieve sperm for an ICSI procedure and perform embryo karyotyping prior to the transfer, given that all were at increased risk of sperm aneuploidy caused by abnormal segregation of the meiotic multivalent. It should be noted that these carriers of balanced translocations are at increased risk of having children with malformations due to partial trisomies and monosomies that are not as lethal as complete trisomies and monosomies. Only one of them, a carrier of a translocation $(Y ; 11)$, underwent testicular biopsy, but no sperm was retrieved. Histology tests revealed arrested spermatogenesis at the level of primary spermatocytes. Cytogenetic studies showed meiosis progressed until the metaphase I stage (Fig. 1).

A patient with azoospermia had a Robertsonian trans- 
1a. Mitotic metaphase showing the Reciprocal Translocation between the chromosomes $Y$ and 11

1b. Chain configuration of the quadrivalent $Y ; 11$ during the metaphase of the primary spermatocyte.

1c. Synaptonemal complex in pachytene spermatocyte

1d: Schematic configuration of the meiotic quadrivalent

1e. Meiosis arrest in primary spermatocyte
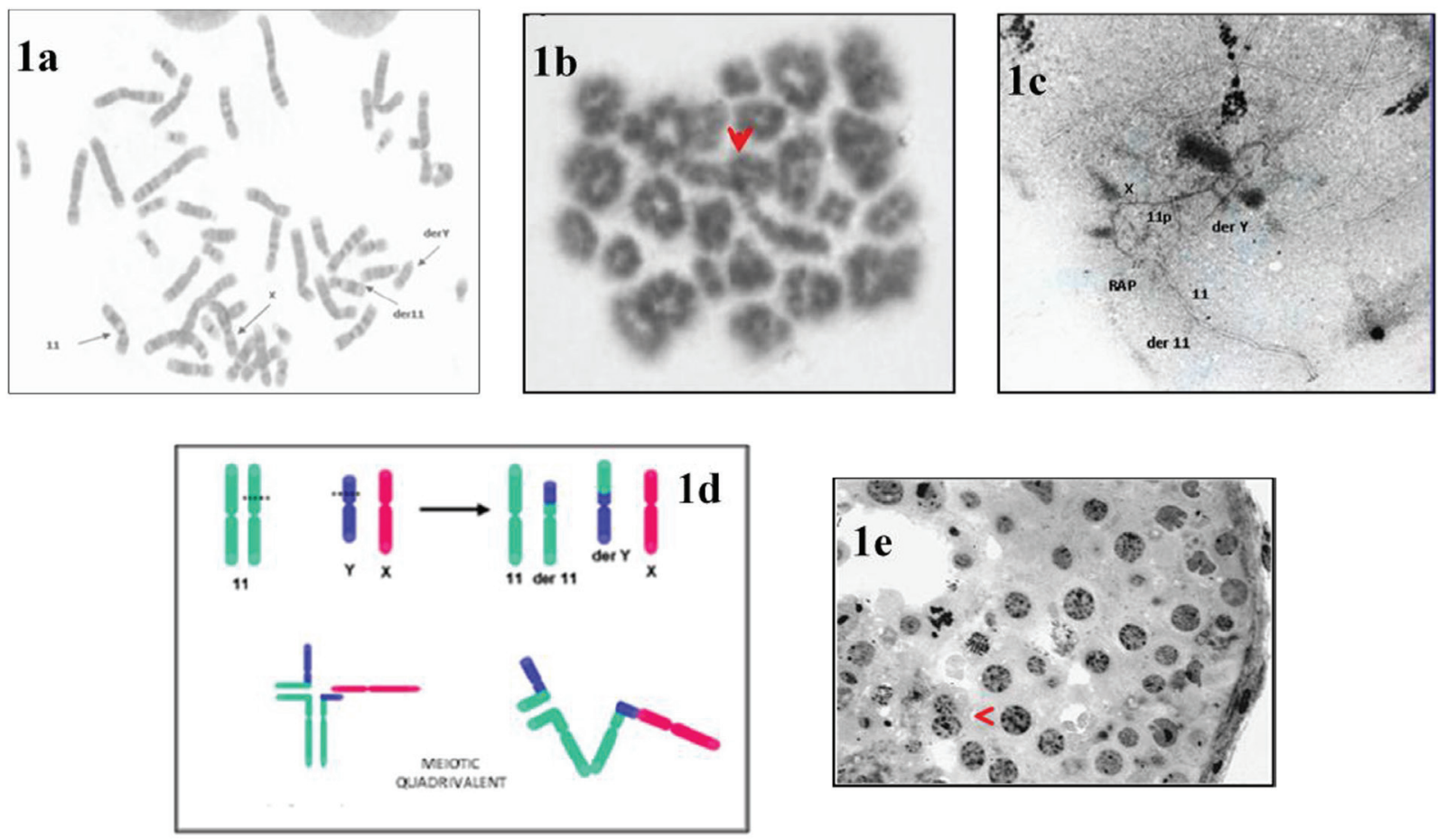

location $(13 ; 14)$. This anomaly is the most common chromosomal rearrangement. Its phenotypic expression varies significantly, ranging from men with normozoospermia to azoospermia, although most patients have moderate oligozoospermia. Although from a theoretical point of view a carrier of a centric fusion has a chance of $75 \%$ of producing unbalanced spermatozoa, the empirical risk is much lower, never exceeding 30\% (Coco et al., 2005).

Additionally, the children of carriers have a $1 \%$ chance of presenting chromosomal abnormalities (Coco, 2011). Therefore, it is questionable whether all carriers of centric fusions should undergo PGD, except when the severity of the semen abnormality makes them candidates for ICSI. The situation of carriers of autosomal reciprocal translocations in which the risk of abnormal sperm equals or exceeds the theoretical risk is very different. In such cases, the risk of birth malformations ranges between $5 \%$ and $10 \%$ (Sciurano et al., 2012).

A patient had a pericentric inversion loop on chromosome 18. Although the theoretical risk of this finding causing gamete aneuploidy by meiotic segregation is $66 \%$, the empirical risk is much lower, and depends mainly on the chromosome involved and the size of the segment invested. The patient was informed of the available prenatal diagnostic tests.

A phenotypically normal patient with oligozoospermia was surprisingly found to have an additional segment in the short arm of chromosome 22. Although the origin of the segment could not be determined, a trivalent formed during meiosis might subsequently undergo abnormal segregation, requiring the assisted reproduction procedure to be preceded by blastocyst molecular karyotyping.

Polymorphic variants were found in about $12 \%$ of the patient with azoospermia and oligozoospermia. Most of

them were due to constitutive heterochromatin of various lengths. The expression of polymorphisms varies. Some authors believe polymorphisms are normal chromosome variants, while others have correlated variants such as 9qh + and 9ph with sterility (Coco et al., 1986; Gallego \& Coco, 1988; Madon et al., 2005, García-Peiró et al., 2011). The association with sperm production probably depends on the size and location of heterochromatic block, particularly when euchromatin is involved in the polymorphism, since it might produce asynaptic or desynaptic mutations during meiosis.

To sum up with, $13 \%$ of the 141 patients with abnormal semen included in this study had chromosomal abnormalities, most of which causing infertility and significant risk for their offspring. Polymorphic variants were observed in $25 \%$ of the patients. Although most of them are deemed morphologically normal, further studies are needed to correlate the polymorphisms with the synaptonemal complex during meiosis, to thus clarify their roles.

\section{Acknowledgements}

The authors would like to thank Dr. Marta Susana Gallego for her invaluable support.

\section{CONFLICT OF INTERESTS}

No conflict of interest have been declared.

\section{Corresponding author:}

María Noelia Poli

Laboratorio de Genética Department of Biología FCEyN

Mar del Plata - Argentina

E-mail: noeliamdp@gmail.com 


\section{REFERENCES}

Coco R, Gallego MS, Brugo S, Carrere C, Nicholson R. Cytogenetic findings in 301 sterile and/or infertile men with abnormal spermograms. Medicina (B Aires). 1986;46:303-10.

Coco R, Coco Ludueña F, Urquiza M, Mincman J, Gallo A, Gismondi F, Neuspiller N. Riesgo Genético reproductivo en Portadores de Rearreglos cromosómicos. Reproducción. 2005;20: 25-36.

Coco R. Genética y Fertilización en el Factor Masculino. Rev Argent Androl. 2011; 28:36-43.

Coco R. Anomalías Cromosómicas y Génicas e Infertilidad. In: Mackena A, ed. Reproducción Humana e Infertilidad. Santiago de Chile: Mediterraneo, 2013. p. 172-91.

Coco R. Pacientes con mayor riesgo de anomalías genéticas en la descendencia. In: Peña E P, Red Latinoamericana de Reproducción Asistida ed. Manual de Procedimientos Clínicos en Reproducción Medicamente Asistida. 2015. p. 133-6.

Dutrillaux B. [Various banding simultaneously obtained on the same slides, after treat- ment by BrdU]. Humangenetik. 1975;30:297-306.

Gallego MS, Coco R. Non-disjunction and parental karyotypes. Medicina (B Aires). 1988;48:147-55.

García-Peiró A, Oliver-Bonet M, Navarro J, Abad C, Guitart $\mathrm{M}$, Amengual MJ, Benet J. Sperm DNA Integrity and Meiotic Behavior Assessment in an Infertile Male Carrier of a 9qh+++ Polymorphism. J Biomed Biotechnol. 2011; 2011:730847

Madon PF, Athalye AS, Parikh FR. Polymorphic variants on chromosomes probably play a significant role in infertility. Reprod Biomed Online. 2005;11:726-32.

Moorhead PS, Nowell PC, Mellman WJ, Battips DM, Hungerford DA. Chromosome preparation of leucocytes cultured from human peripheral blood. Exp Cell Res. 1960; 20:613-6.

Sciurano RB, Rahn MI, Rey-Valzacchi G, Coco R, Solari AJ. The role of asynapsis in human spermatocyte failure. Int J Androl. 2012; 35:541-9.

Seabright M. Human chromosome banding. Lancet. 1972; $1: 967$. 